\title{
Measurement of serum and vitreous concentrations of anti-type II collagen antibody in diabetic retinopathy
}

This article was published in the following Dove Press journal:

Clinical Ophthalmology

20 March 2015

Number of times this article has been viewed

\author{
Atsuko Nakaizumi' \\ Masanori Fukumoto' \\ Teruyo Kida' \\ Hiroyuki Suzuki' \\ Seita Morishita' \\ Takaki Satou' \\ Hidehiro Oku' \\ Tsunehiko Ikeda' \\ Kimitoshi Nakamura ${ }^{2}$ \\ 'Department of Ophthalmology, \\ Osaka Medical College, Takatsuki City, \\ Osaka, ${ }^{2}$ Nakamura Eye Clinic, Nagano, \\ Japan
}

Background: Autoimmune mechanisms have been postulated as a cause of diabetic retinopathy (DR), as several autoantibodies have reportedly been detected in the serum of DR patients. In this present study, we measured serum and vitreous levels of anti-type II collagen (anti-II-C) antibodies in DR patients and investigated their association with the mechanism of development of DR.

Patients and methods: Blood samples were obtained from patients with proliferative DR and from patients with diabetic macular edema who underwent vitrectomy at Osaka Medical College, Takatsuki City, Osaka, Japan. Diabetic patients without DR were also included. The control group consisted of age- and sex-matched patients with noninflammatory eye diseases who underwent eye surgery for retinal detachment or for cataracts. The levels of anti-II-C immunoglobulin $(\mathrm{Ig}) \mathrm{G}$ antibody in the vitreous and serum were measured using a human/ monkey anti-II-C IgG assay kit.

Results: The serum levels of anti-II-C IgG antibody were significantly higher in the DR patients than in the patients with noninflammatory eye disease $(56.8 \pm 33.8$ units $/ \mathrm{mL}$ versus $30.5 \pm 13.7$ units/mL, respectively; $P<0.05$, Fisher's exact test). These levels were also significantly higher in the diabetic patients without DR than in the patients with noninflammatory eye disease $(76.3 \pm 49.7$ units $/ \mathrm{mL}$ versus $30.5 \pm 13.7$ units $/ \mathrm{mL}$, respectively; $P<0.01$, Fisher's exact test). However, anti-II-C IgG antibody levels were unable to be detected in all of the obtained vitreous fluid samples.

Conclusion: The development and progression of DR may be related to a mechanism involving intraocular type II collagen, which normally has immunological tolerance as a sequestered antigen. In DR, the disruption of the blood-retinal barrier leads to contact between the intraocular type II collagen and immunocompetent cells, and to subsequent activation of the autoimmune mechanism.

Keywords: blood-retinal barrier, autoimmune mechanism, vitreous, serum

\section{Introduction}

The development of diabetic retinopathy (DR) is now generally thought to be due to chronic inflammation. Evidence for this includes the following clinical findings in patients with DR: 1) increased blood levels of inflammatory biomarkers such as C-reactive protein; 2) increased vitreous levels of inflammatory cytokines such as tumor necrosis factor alpha, interleukin (IL)-1, and IL-6; and 3) infiltration of inflammatory cells such as neutrophils, macrophages, and lymphocytes (which are normally not found in the eye) into proliferative tissue collected during vitrectomy. ${ }^{1-5}$ Autoimmune mechanisms have also been postulated as a cause of DR. ${ }^{6}$
Correspondence: Tsunehiko lkeda Department of Ophthalmology, Osaka Medical College, 2-7 Daigaku-cho, Takatsuki City, Osaka 569-8686, Japan Tel $+8 I 726846434$

Fax +81726820995

Email tikeda@poh.osaka-med.ac.jp 
Autoimmune diseases are characterized by large individual differences in disease development and progression. This is largely due to the polymorphism of histocompatibility antigen $(H L A)$ genes involved in immune reactions. ${ }^{7}$ However, some patients, even those with long-term poor glycemic control, still fail to develop DR despite the absence of factors like optic atrophy or high myopia that may aid in its prevention. On the other hand, some patients develop proliferative DR in a relatively short period of time. These large individual differences in disease progression support the idea that autoimmunity plays a role in DR. Moreover, polymorphism of $H L A-D R$ which, among HLA genes, is strongly associated with autoimmune disease, has also been reported to play a role in DR progression. ${ }^{8-10}$ Several autoantibodies seen in autoimmune disorders have also been seen in the serum and lacrimal fluid of DR patients. ${ }^{11-15}$

Rheumatoid arthritis (RA) is one of the typical autoimmunity-related diseases. Type II collagen is present in articular cartilage, and autoantibodies to type II collagen are found in patients with RA. ${ }^{16,17}$ When animals are immunized with type II collagen and an adjuvant, RA-like lesions in their joints have been reported to develop. ${ }^{18}$ Moreover, autoimmune reactions to type II collagen are reportedly involved in the development of RA. In patients with RA, after chronic joint inflammation develops, neovascularization due to vascular endothelial growth factor (VEGF) occurs and synovial cells lining the inner layer of joint capsules increase to form proliferative tissue with blood vessels, which is called "pannus" ${ }^{19}$ Meanwhile, in DR, as in RA, neovascularization due to VEGF occurs, glial cells (Muller cells) proliferate, and a proliferative membrane forms in the vitreous. If the stage of simple retinopathy is regarded as a state of chronic inflammation of the retina, then the form of progression to DR may be very similar to RA.

Type II collagen is involved in the pathogenesis of RA, and besides being present in joint cartilage in adults, it is also found in the vitreous. Therefore, we measured the serum and vitreous levels of anti-type II collagen (anti-II-C) antibodies in DR patients and investigated their association with the mechanism of development of DR.

\section{Patients and methods}

Blood samples were obtained from patients with proliferative DR and from patients with diabetic macular edema who underwent a vitrectomy at Osaka Medical College, Takatsuki City, Osaka, Japan. Diabetic patients without DR were also included. The control group consisted of age- and sex-matched patients with noninflammatory eye diseases who underwent eye surgery for retinal detachment or for cataracts. With the exception of the cataract patients, vitreous fluid samples were obtained from all patients. Patients were excluded from the study if their blood samples were positive for rheumatoid factor, they exhibited symptoms of RA, or they had inflammatory eye diseases. We also excluded patients if they had vitreous hemorrhage or if they had previously undergone any other eye surgeries. This study was conducted in accordance with the tenets set forth in the Declaration of Helsinki, and informed consent was obtained from each patient prior to the initiation of the study.

\section{Anti-II-C IgG antibody measurement}

For the measurement of anti-II-C immunoglobulin (Ig)G antibody, blood samples were first centrifuged with the obtained blood serum and then diluted 20-fold using a sample/standard dilution buffer. After the addition of $50 \mu \mathrm{L}$ of collagenase (Sigma-Aldrich Co., St Louis, MO, USA), hyaluronidase (Sigma-Aldrich Co.), and $1 \mu \mathrm{L}$ of calcium chloride dehydrate (Nakarai Tesque, Inc., Kyoto, Japan), the vitreous samples were incubated at room temperature for 1 hour. The samples were then diluted 20 -fold by adding $125 \mu \mathrm{L}$ of $10 \mathrm{mM}$ EDTA/0.02\% sodium azide/phosphate buffered saline and $250 \mu \mathrm{L}$ of sample/standard dilution buffer. The samples were then stored at $-20^{\circ} \mathrm{C}$ until the experiment was performed. The levels of anti-II-C IgG antibody in the vitreous and serum were measured using a human/monkey anti-II-C IgG assay kit (Chondrex, Inc., Redmond, WA, USA) according to the manufacturer's instructions. To correct for any false positive reactions caused by the adhesive Igs contained in the samples, we first determined a unique nonspecific background value for each of the individual samples by using antigen-noncoated wells. We then subtracted this from the value determined in the antigen-coated wells in order to obtain the correct result of the antigen-antibody reaction.

\section{Statistical analysis}

Statistical analysis was performed using Fisher's exact test. A $P$-value of $\leq 0.05$ was considered statistically significant.

\section{Results}

Of the total 47 patients included in this study, blood samples were obtained from 17 patients with DR, 14 diabetic patients without DR, and 16 control patients (nine with retinal detachment and seven with cataract). The clinical characteristics of the patients in each of these three groups are shown in Table 1. During the actual surgery, we also obtained vitreous samples 
Table I Clinical characteristics of the three groups of patients involved in this study

\begin{tabular}{llll}
\hline & $\begin{array}{l}\text { Patients } \\
\text { with DR }\end{array}$ & $\begin{array}{l}\text { Diabetic patients } \\
\text { without DR }\end{array}$ & Control patients \\
\hline $\mathrm{N}$ & 17 & 14 & 16 \\
Male/female & $1 \mathrm{I} / 6$ & $9 / 5$ & $1 \mathrm{I} / 5$ \\
Mean age, years & $55.8 \pm 9.1$ & $65.4 \pm 10.7$ & $59.4 \pm 21.0$ \\
\hline
\end{tabular}

Abbreviations: DR, diabetic retinopathy; $\mathrm{N}$, number.

from 15 patients with DR and five patients with retinal detachment.

The serum levels of the anti-II-C IgG antibody were significantly higher in the DR patients than in the patients with noninflammatory eye disease $(56.8 \pm 33.8$ units $/ \mathrm{mL}$ versus $30.5 \pm 13.7$ units $/ \mathrm{mL}$, respectively; $P<0.05$, Fisher's exact test) (Figure 1).These levels were also significantly higher in the diabetic patients without DR than in the patients with noninflammatory eye disease $(76.3 \pm 49.7$ units $/ \mathrm{mL}$ versus $30.5 \pm 13.7$ units $/ \mathrm{mL}$, respectively; $P<0.01$, Fisher's exact test) (Figure 1). However, anti-II-C IgG antibody levels were unable to be detected in all of the obtained vitreous fluid samples. The detection levels from the vitreous samples was $<5$ units $/ \mathrm{mL}$.

\section{Discussion}

Cartilage and vitreous, which contain type II collagen, are both avascular tissues. As a result, type II collagen is considered to be a sequestered antigen that is able to escape surveillance of the immunocytes circulating in the blood throughout the body, and thus has immunological tolerance. ${ }^{20-22}$ Although the reason remains unknown, in RA there is a loss of the immunological tolerance that leads to the development of various autoantibodies, including anti-II-C antibodies, and the progression of articular tissue destruction due to an autoimmune response.

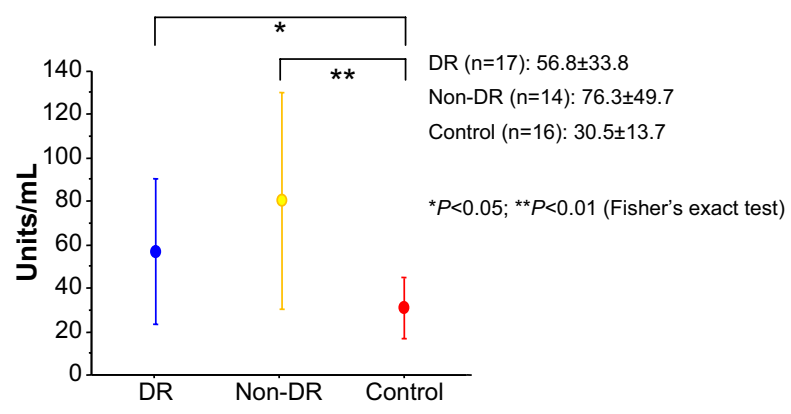

Figure I Serum levels of anti-II-C IgG antibody.

Notes: The serum levels of anti-II-C IgG antibody (units $/ \mathrm{mL}$ ) were significantly higher in the DR patients than in the patients with noninflammatory eye disease. Moreover, those levels were also significantly higher in the diabetic patients without DR than in the patients with noninflammatory eye disease.

Abbreviations: DR, diabetic retinopathy; anti-II-C, anti-type II collagen; Ig, immunoglobulin.
In addition, serum levels of anti-II-C antibodies are also increased in RA and play a role in the pathogenesis of other diseases in which cartilage is destroyed, including osteoarthritis, ${ }^{23}$ relapsing polychondritis, ${ }^{24}$ systemic lupus erythematosus with arthritis, ${ }^{25}$ and temporomandibular arthritis. ${ }^{26}$ The inner ear (and part of the auditory ossicles) also contains cartilage, and in diseases of the inner ear such as Ménière's disease, otosclerosis, and autoimmune ear disease, serum titers of anti-II-C antibodies are increased. ${ }^{27,28}$ In addition, as in RA, when type II collagen is injected into animals, pathology resembling Ménière's disease is reported to occur. ${ }^{29}$ Thus, in diseases where the inner ear is attacked, an autoimmune response to type II collagen is thought to play a role.

Balashova et $\mathrm{al}^{15}$ reported increased serum and lacrimal fluid anti-II-C antibodies and immune complexes in patients with DR. In this present study, serum levels of anti-II-C antibodies were also increased in diabetic patients with and without DR. However, the mechanism for the increase of serum anti-II-C antibodies in diabetic patients remains unclear.

As mentioned earlier, the vitreous, together with joints and the inner ear, is one of the few tissues in which type II collagen is present in adults. In RA and Ménière's disease, in which cartilage is damaged, anti-II-C antibodies are related to the pathogenesis. Thus, there may be a similar mechanism in DR involving vitreoretinal lesions.

Interestingly, the three tissues in which type II collagen is present - ie, joints, the inner ear, and vitreous - contain synovial fluid, lymph, and vitreous humor, respectively. Because of the blood-joint barrier, blood-labyrinth barrier, and blood-retinal (ocular) barrier, these fluids are sequestered from the immunocytes in the blood. ${ }^{30-32}$ However, in DR, there is persistent hyperglycemia that disrupts the blood-retinal barrier which, in turn, leads to an increase in the vascular permeability and the occurrence of macular edema. As the lesions progress in RA and Ménière's disease, hydrarthrosis and endolymphatic hydrops also occur. Moreover, the barrier function is disrupted, vascular permeability increases, and immunological tolerance may be lost in these diseases.

Previous studies have reported finding an increase in the anti-II-C antibodies in the synovial fluid of RA patients, and in the endolymph of Ménière's disease and autoimmune ear disease patients. ${ }^{16,27,33}$ However, with the exception of one patient with mild preretinal hemorrhage, we were unable to detect anti-II-C antibodies in the vitreous humor of any of our DR patients. The reason for these findings may be related to differences between the vitreous and the synovial fluid and endolymph. Although the synovial fluid and endolymph do contain a precursor type II procollagen with a different 
antigenicity, no type II collagen is present. In contrast, the vitreous humor does contain type II collagen. Thus, its presence may have interfered with our measurements and prevented the detection of any anti-II-C antibodies. Even though the vitreous samples were treated with collagenase in our current experiment, the enzyme-linked immunosorbent reactions may have been blocked due to the binding of the anti-II-C antibodies to the remaining collagen that was not enzymatically degraded, or to the collagen degradation products.

In RA, immune complexes and complement titers are elevated in the serum and synovial fluid, and the immune complexes precipitate in the tissues. Therefore, the joint lesions are thought to be due to a localized type III (Arthus) allergic reaction. This is supported by the fact that fibrinoid degeneration is a pathological feature of the Arthus-type allergic reactions, with fibrin precipitates reported to occur in the synovium in RA patients. ${ }^{34}$

In addition, it has also been reported that there are elevated immune complexes and complement titers in the serum of DR patients. A previous study that examined DR patients reported finding increased hard exudates in the retina in simple diabetes, fibrin precipitates in the hard exudates, and increased fibrinoid reactions after intraocular surgery. ${ }^{35}$ Furthermore, it has also been found that there is precipitation of antibodies and complement components in the retinal tissue of DR patients, with these precipitated antibodies and complement presumably forming immune complexes with antigens in the retina. ${ }^{36}$ Therefore, similar to RA, DR may develop due to an Arthus reaction (localized immune-complex lesions). Since the amount of antibodies far exceeds the amount of antigens in the blood, there is no formation of immune complexes. However, similar amounts of antibodies and antigens occur in the peripheral tissues and thus, precipitation of the immune complexes and the formation of lesions. Consequently, immunosuppressive therapy may potentially become a new treatment pathway for DR in the future. In fact, to some extent, this has already been suggested in previously published reports. ${ }^{37-40}$

Since the retina is formed during development by protrusion of the brain tissue, the structures of the retinal and cerebral blood vessels are very similar. In fact, cerebral arteriosclerosis can be assessed during clinical examinations by evaluating the appearance of the retinal blood vessels. However, even if diabetes persists, capillary aneurysms and hard exudates that are seen in DR do not occur in the brain tissue, and there is no observed occurrence of parenchymal hemorrhage or neovascularization. ${ }^{41,42}$ The differences noted between the cerebral and retinal blood vessels in diabetes may be because type II collagen is found in the vitreous but not in the brain. Moreover, our observation that there are differences in the responses supports our theory that DR occurs due to an immune response to type II collagen.

\section{Conclusion}

The findings of this study show that the development and progression of DR may be related to a mechanism involving intraocular type II collagen, which normally has immunological tolerance as a sequestered antigen. In DR, hyperglycemia causes disruption of the blood-retinal barrier, which leads to contact between the intraocular type II collagen and immunocompetent cells, and to the subsequent activation of the autoimmune mechanism. To definitively clarify the relationship between DR and autoimmunity, further investigations are needed.

\section{Acknowledgment}

The authors wish to thank John Bush for reviewing the manuscript.

\section{Disclosure}

The authors report no conflicts of interest in this work.

\section{References}

1. McLeod DS, Lefer DJ, Merges C, Lutty GA. Enhanced expression of intracellular adhesion molecule-1 and P-selectin in the diabetic human retina and choroid. Am J Pathol. 1995;147(3):642-653.

2. Lutty GA, Cao J, McLeod DS. Relationship of polymorphonuclear leukocytes to capillary dropout in the human diabetic choroid. Am J Pathol. 1997;151(3):707-714.

3. van Hecke MV, Dekker JM, Nijpels G, et al. Inflammation and endothelial dysfunction are associated with retinopathy: the Hoorn Study. Diabetologia. 2005;48(7):1300-1306.

4. Suzuki Y, Nakazawa M, Suzuki K, Yamazaki H, Miyagawa Y. Expression profiles of cytokines and chemokines in vitreous fluid in diabetic retinopathy and central retinal vein occlusion. Jpn J Ophthalmol. 2011;55(3):256-263.

5. Kase S, Saito W, Ohno S, Ishida S. Proliferative diabetic retinopathy with lymphocyte-rich epiretinal membrane associated with poor visual prognosis. Invest Ophthalmol Vis Sci. 2009;50(12):5909-5912.

6. Kastelan S, Zjacić-Rotkvić V, Kastelan Z. Could diabetic retinopathy be an autoimmune disease? Med Hypotheses. 2007;68(5): 1016-1018.

7. Möller E, Persson B, Sterky G. HLA phenotypes and diabetic retinopathy. Diabetologia. 1978;14(3):155-158.

8. Awa WL, Boehm BO, Rosinger S, et al; DPV Initiative and the German BMBF Competence Networks Diabetes Mellitus and Obesity. HLA-typing, clinical, and immunological characterization of youth with type 2 diabetes mellitus phenotype from the German/Austrian DPV database. Pediatr Diabetes. 2013;14(8):562-574.

9. Minuto N, Emmanuele V, Vannati M, et al. Retinopathy screening in patients with type 1 diabetes diagnosed in young age using a nonmydriatic digital stereoscopic retinal imaging. J Endocrinol Invest. 2012;35(4):389-394.

10. Mimura T, Funatsu H, Uchigata Y, et al. Glutamic acid decarboxylase autoantibody prevalence and association with HLA genotype in patients with younger-onset type 1 diabetes and proliferative diabetic retinopathy. Ophthalmology. 2005;112(11):1904-1909. 
11. Petty RG, Pottinger BE, Greenwood RM, Pearson JD, Mahler RF. Diabetes is associated with a high incidence of endothelial-binding antibodies which do not correlate with retinopathy, von Willebrand factor, angiotensin-converting enzyme or C-reactive protein. Diabetes Res.1991;17(3):115-123.

12. Nayak RC, Agardh CD, Kwok MG, Stjernquist H, Farthing-Nayak PJ, Agardh E. Circulating anti-pericyte autoantibodies are present in Type 2 diabetic patients and are associated with non-proliferative retinopathy. Diabetologia. 2003;46(4):511-513.

13. Nayak RC, Lynch K, Gustavsson C, et al. Circulating antipericyte autoantibodies: a novel modifier of risk of progression of diabetic retinopathy? Retina. 2007;27(2):211-215.

14. Attawia MA, Nayak RC. Circulating antipericyte autoantibodies in diabetic retinopathy. Retina. 1999;19(5):390-400.

15. Balashova LM, Zaĭtseva NS, Teplinskaia LE, et al. Antibodies to types II and IV collagens, tumor necrosis factor-alpha and circulating immune complexes in lacrimal fluid and serum of patients with diabetic retinopathy and different stages. Vestn Oftalmol. 2000;116(3):31-34. Russian.

16. Cook AD, Rowley MJ, Mackay IR, Gough A, Emery P. Antibodies to type II collagen in early rheumatoid arthritis. Correlation with disease progression. Arthritis Rheum. 1996;39(10):1720-1727.

17. Fujii K, Tsuji M, Kitamura A, Murota K. The diagnostic significance of anti-type II collagen antibody assay in rheumatoid arthritis. Int Orthop. 1992;16(3):272-276.

18. Nandakumar KS, Svensson L, Holmdahl R. Collagen type II-specific monoclonal antibody-induced arthritis in mice: description of the disease and the influence of age, sex, and genes. Am J Pathol. 2003;163(5):1827-1837.

19. Afuwape AO, Kiriakidis S, Paleolog EM. The role of the angiogenic molecule VEGF in the pathogenesis of rheumatoid arthritis. Histol Histopathol. 2002;17(3):961-972.

20. Keino H, Takeuchi M, Kezuka T, et al. Induction of eye-derived tolerance does not depend on naturally occurring $\mathrm{CD} 4^{+} \mathrm{CD} 25^{+} \mathrm{T}$ regulatory cells. Invest Ophthalmol Vis Sci. 2006;47(3):1047-1055.

21. Stein-Streilein J, Streilein JW. Anterior chamber associated immune deviation (ACAID): regulation, biological relevance, and implications for therapy. Int Rev Immunol. 2002;21(2-3):123-152.

22. Sonoda KH, Sakamoto T, Qiao H, et al. The analysis of systemic tolerance elicited by antigen inoculation into the vitreous cavity: vitreous cavityassociated immune deviation. Immunology. 2005;116(3):390-399.

23. Klareskog L, Johnell O, Hulth A, Holmdahl R, Rubin K. Reactivity of monoclonal anti-type II collagen antibodies with cartilage and synovial tissue in rheumatoid arthritis and osteoarthritis. Arthritis Rheum. 1986; 29(6):730-738.

24. Joliat T, Seyer J, Bernstein J, et al. Antibodies against a 30 kilodalton cochlear protein and type II and IX collagens in the serum of patients with inner ear diseases. Ann Otol Rhinol Laryngol. 1992;101(12): 1000-1006.

25. Yajima K, Nakamura A, Sugahara A, Takai T. FcgammaRIIB deficiency with Fas mutation is sufficient for the development of systemic autoimmune disease. Eur J Immunol. 2003;33(4):1020-1029.

26. Salo LA, Raustia AM. Type II and type III collagen in mandibular condylar cartilage of patients with temporomandibular joint pathology. J Oral Maxillofac Surg. 1995;53(1):39-44; discussion 45.
27. Yoo TJ, Stuart JM, Kang AH, Townes AS, Tomoda K, Dixit S. Type II collagen autoimmunity in otosclerosis and Meniere's Disease. Science. 1982;217(4565):1153-1155.

28. Yoshino K, Ohashi T, Urushibata T, Kenmochi M, Akagi M. Antibodies of type II collagen and immune complexes in Menière's disease. Acta Otolaryngol Suppl. 1996;522:79-85.

29. Yoo TJ, Yazawa Y, Tomoda K, Floyd R. Type II collagen-induced autoimmune endolymphatic hydrops in guinea pig. Science. 1983;222(4619): 65-67.

30. Levick JR, Knight AD. Osmotic flows across the blood-joint barrier. Ann Rheum Dis. 1987;46(7):534-539.

31. Juhn SK, Hunter BA, Odland RM. Blood-labyrinth barrier and fluid dynamics of the inner ear. Int Tinnitus J. 2001;7(2):72-83.

32. Cunha-Vaz J. The blood-ocular barriers. Surv Ophthalmol. 1979;23(5):279-296.

33. Hester RB, Bennett JC. Rheumatoid arthritis: an immune complex disease? A review of the reaction of antigen with antibody to form immune complexes and the mechanisms by which they mediate tissue injury. Geriatrics. 1973;28(6):84-91.

34. Hashimoto H, Okada T, Nagase K, Shiokawa Y. The intra-articular residual rate of $131 \mathrm{I}$-fibrinogen and microautoradiographs of the synovial tissue in rheumatoid arthritis. Scand J Rheumatol. 1977;6(3): 137-143.

35. Danilova AI, Dekhtiareva OS. Cellular immunity in patients with diabetes mellitus complicated by diabetic retinopathies. Probl Endokrinol (Mosk). 1984;30(5):29-34. Russian.

36. Gerl VB, Bohl J, Pitz S, Stoffelns B, Pfeiffer N, Bhakdi S. Extensive deposits of complement $\mathrm{C} 3 \mathrm{~d}$ and $\mathrm{C} 5 \mathrm{~b}-9$ in the choriocapillaris of eyes of patients with diabetic retinopathy. Invest Ophthalmol Vis Sci. 2002;43(4):1104-1108.

37. Dugel PU, Blumenkranz MS, Haller JA, et al. A randomized, doseescalation study of subconjunctival and intravitreal injections of sirolimus in patients with diabetic macular edema. Ophthalmology. 2012;119(1):124-131

38. Zong YJ, Shen Q, Zhang XD, Lei B, Fang YH, Chen XM. The protective effects on the function and structure of retinae in diabetic rats by intravitreal injection of cyclosporin A. Zhonghua Yan Ke Za Zhi. 2012;48(7):591-597. Chinese.

39. Zhang X, Cui J, Qiu MC, Li DQ, Zhang P, Zhang JS. The effects of cyclosporine A on immunoglobulins deposition in retina of streptozotocin-induced diabetic rats. Zhonghua Nei Ke Za Zhi. 2008;47(2): 125-128. Chinese.

40. Carmo A, Cunha-Vaz JG, Carvalho AP, Lopes MC. Effect of cyclosporin-A on the blood-retinal barrier permeability in streptozotocininduced diabetes. Mediators Inflamm. 2000;9(5):243-248.

41. Wong HC, Elts SM, Phillips JW, Williams KA. Differential growth of brain and retinal bovine pericytes. Diabetologia. 1992;35(9): $818-827$.

42. Cogan DG, Kuwabara T. Comparison of retinal and cerebral vasculature in trypsin digest preparations. Br J Ophthalmol. 1984;68(1):10-12.
Clinical Ophthalmology

\section{Publish your work in this journal}

Clinical Ophthalmology is an international, peer-reviewed journal covering all subspecialties within ophthalmology. Key topics include: Optometry; Visual science; Pharmacology and drug therapy in eye diseases; Basic Sciences; Primary and Secondary eye care; Patient Safety and Quality of Care Improvements. This journal is indexed on Submit your manuscript here: http://www.dovepress.com/clinical-ophthalmology-journal

\section{Dovepress}

PubMed Central and CAS, and is the official journal of The Society of Clinical Ophthalmology (SCO). The manuscript management system is completely online and includes a very quick and fair peer-review system, which is all easy to use. Visit http://www.dovepress.com/ testimonials.php to read real quotes from published authors. 